\title{
Maternal and neonatal outcomes and determinants of iodine deficiency in third trimester of pregnancy in an iodine sufficient area
}

Soraya Saleh Gargari ${ }^{1}$, Reyhaneh Fateh ${ }^{2}$, Mina Bakhshali-bakhtiari ${ }^{1}$, Masoumeh Saleh², Masoumeh Mirzamoradi ${ }^{*}$ and Mahmood Bakhtiyari, ${ }^{3,4}$

\begin{abstract}
Background: Mild to moderate iodine deficiency in pregnant women may expose them to the increased risk of the development of goiter and thyroid disorder. There is a relationship between low maternal UIC (Urinary iodine concentration) in pregnancy and diminished placental weight and neonatal head circumference. The current study was an attempt to assess iodine nutritional status, its determinants and relationship with maternal and neonatal outcomes.

Methods: In this population based cross-sectional study, which was conducted from April 2017 to September 2018, information was collected from 884 women of 20-45 years old who referred for periodic pregnancy visits. UIC was measured in random urine samples by applying a manual method which was based on the Sandell-Kolthoff technique. Information related to neonatal and maternal complications was collected from the individuals enrolled in the study through systematic follow-ups of the research team in each hospitals and the referral of trained midwives to the place of delivery and the retrieval of the case files.

\footnotetext{
* Correspondence: drmoradio00@yahoo.com

${ }^{2}$ Department of Gynecology \& Obstetrics, Mahdiyeh Hospital, Shahid Beheshti University of Medical Sciences, Tehran, Iran

Full list of author information is available at the end of the article
}

(c) The Author(s). 2020 Open Access This article is licensed under a Creative Commons Attribution 4.0 International License, which permits use, sharing, adaptation, distribution and reproduction in any medium or format, as long as you give appropriate credit to the original author(s) and the source, provide a link to the Creative Commons licence, and indicate if changes were made. The images or other third party material in this article are included in the article's Creative Commons licence, unless indicated otherwise in a credit line to the material. If material is not included in the article's Creative Commons licence and your intended use is not permitted by statutory regulation or exceeds the permitted use, you will need to obtain permission directly from the copyright holder. To view a copy of this licence, visit http://creativecommons.org/licenses/by/4.0/. The Creative Commons Public Domain Dedication waiver (http://creativecommons.org/publicdomain/zero/1.0/) applies to the data made available in this article, unless otherwise stated in a credit line to the data. 


\begin{abstract}
(Continued from previous page)
Results: The results showed that out of 884 participants 838 (94.8\%) had a urinary iodine concentration of more than 150 micrograms/litre and 46 (5.2\%) showed urinary iodine concentrations less than 150 micrograms/litre. The median (IQR) urinary iodine concentration in the third trimester was $176(165-196) \mu \mathrm{g} / \mathrm{l}$. According to the WHO criteria 46 of the participants (5.2\%) had insufficient urinary iodine concentrations, 805 (91.06\%) had adequate urinary iodine concentrations while 33 (3.73\%) showed more than adequate levels. There were no participants with urinary iodine concentrations higher than 500 micrograms/litre. The main influencing factors on maternal iodine deficiency in this study were weight gain during pregnancy (Odds Ratio $(O R)=0.88,95 \% \mathrm{Cl}$ : 0.82-0.95), number of previous pregnancy $(\mathrm{OR}=0.59,95 \% \mathrm{Cl}$ : 0.39-0.89) the interval between the most recent pregnancies ( $\mathrm{OR}=0.78,95 \% \mathrm{Cl}: 0.64-0.95)$, whether or not the pregnancy has been Planned ( $\mathrm{OR}=2.92,95 \% \mathrm{Cl}$ : 1.29-6.58) and nutritional complement consumption $(\mathrm{OR}=3.64,95 \% \mathrm{Cl}$ : 1.44-9.1). The need for a neonatal intensive care unit (NICU) admission (OR=4.64, 95\% Cl: 1.81-11.9) and preterm birth $(\mathrm{OR}=3.29,95 \% \mathrm{Cl}: 1.51-7.1)$ were significantly related with maternal iodine deficiency before delivery. Also there is no significant differences regarding the mean maternal urinary iodine concentration between the normal and different maternal complications groups $(p=0.47)$.
\end{abstract}

Conclusion: lodine deficiency in pregnant women can be improved by appreciate planning for pregnancy, proper interpregnancy time interval (> 12 months to $<5$ years), appropriate nutrition during pregnancy. Besides, controlling maternal urinary iodine concentrations is important to prevent neonatal complications such as preterm delivery and NICU admission.

Keywords: Urinary iodine concentration, Maternal and neonatal complications, Pregnancy

\section{Background}

Numerous physiologic changes in the production of thyroidal hormone during pregnancy can be observed; thus, an increase in the amount of iodine intake should be considered in order to meet the higher demands which are needed for the production of thyroxine (T4), transferring iodine to the fetus, and increasing the clearance of renal iodine by the mother [1-3]. Due to the elevated production of thyroid hormone, the elevated excretion of renal iodine, and the requirements of fetal iodine, dietary iodine requirements are higher in pregnant adults than non-pregnant ones [4]. Mostly, to determine iodine status in populations, spot urinary iodine values are utilized. Since considerable diurnal and daily variations can be observed in urinary iodine excretion, urinary iodine concentrations (UICs) cannot be applied to detect specific individuals with iodine deficiency $[5,6]$. Women enjoying suitable iodine intake before and during pregnancy have suitable intrathyroidal iodine stores, so they can easily adapt to the increased demand for thyroid hormone during pregnancy. Moreover, total-body iodine levels in these women will be constant during pregnancy [7]. Severe shortage of iodine in pregnant women may give rise to the increased rates of pregnancy loss, stillbirth, and increased perinatal and infant mortality or lead to fetal iodine deficiency damaging neurocognitive growth of the growing fetus [8-11].

Mild to moderate iodine deficiency in pregnant women may expose them to the increased risk of the development of goiter [12] and thyroid disorders [13]. There is a relationship between low maternal UIC in pregnancy and diminished placental weight and neonatal head circumference [14].
The current study was an attempt to assess iodine nutritional status, its determinants and relationship with maternal and neonatal outcomes.

\section{Method}

\section{Study design}

In this population based cross-sectional study, which was conducted from April 2015 to September 2016, information was collected from 884 women of $20-45$ years old who referred for periodic pregnancy visits. The inclusion criteria were singleton pregnancy, not having diabetes, hypertensive disorders of pregnancy, and thyroid diseases, and not taking thyroid medications.

\section{Sampling}

Firstly, a list of all hospitals and medical centers in Tehran was provided and by subsequent phone calls, those hospitals in which the gynecology department was active were entered the initial sample list. Then, the approximate location of hospitals was determined on the standard map of the city of Tehran. Since the hospital admission policies varied widely in Tehran's 22 districts, the effect of the location and socio-economic status were considered by using a systematic random sampling approach. Finally, 6 hospitals (Mahdiyeh hospital from district 16, Emam khomeni hospital from district 6, Emam hossien hospital from district 13, Shohaday tajrish hospital from district 1, Erfan and Bahman hospitals from district 2 were chosen as sampling area) were selected in different areas of North, South, Center, West, and East of Tehran for individual sampling. Considering that the policy of admission and the number of referrals were different in these hospitals, in this study, sampling proportional to the size of 
admission was performed (270 sample from Mahdiyeh hospital, 340 sample from Emam khomeni hospital, 110 sample from Emam hossien hospital, 85 sample from Shohaday tajrish hospital and 84 sample were chosen from Erfan and Bahman hospitals). Sample selection within the each selected hospital was done by using simple random sampling method. In the present study, 19 individuals due to the loss or lack of urine sample, 11 individuals due to the lack of follow up of their newborn because of transmitting to other medical centers, and 24 individuals due to not cooperating with the research team and lacking data were excluded from the study. Finally, data collected from 884 individuals out of a total of 938 individuals who entered into the study were analyzed.

\section{Data collection procedure}

In the present study, maternal basic and demographic data (including age, gestational age, weight gain during pregnancy, mother educational status, smoking, parity, gravidity, time interval between the recent pregnancy and inclusion criteria) were recorded by a trained midwife. In this study, gestational age was calculated based on the first day of the last normal menstruation. Moreover, the gestational age greater than 24 weeks was considered as third trimester of gestation. Information related to neonatal and maternal complications was collected from the individuals enrolled in the study through systematic follow-ups of the research team in each hospitals and the referral of trained midwives to the place of delivery and the retrieval of the case files. The severity of congenital hypothyroidism $(\mathrm{CH})$ is classified based on initial free T4 (FT4) concentrations. we classified $\mathrm{CH}$ as severe $(\mathrm{FT} 4<5 \mathrm{pmol} / \mathrm{L}[<0.39 \mathrm{ng} / \mathrm{dL}])$, moderate (FT4 $5-<10 \mathrm{pmol} / \mathrm{L} \quad[0.39-<0.78 \mathrm{ng} / \mathrm{dL}]$ ), or mild (FT4 $\geq 10$ $[\geq 0.78 \mathrm{ng} / \mathrm{dL}])$ [15].

Urinary iodine concentration (UIC) was measured in random urine samples by applying a manual method which was based on the Sandell-Kolthoff technique. The results are presented as microgram of iodine per liter of urine $(\mu \mathrm{g} / \mathrm{L})$. The analytical sensitivity for iodine was $1.39 \mu \mathrm{g} / \mathrm{L}$ and the intra-assay and interassay coefficients of variation were 4.4 and $3.9 \%$, respectively. In this study the insufficient iodine intake was considered as median urinary iodine less than $150 \mu \mathrm{g} / \mathrm{l}$ in pregnant women [16].

All procedures performed in studies involving human participants were in accordance with the ethical standards of the institutional and/or national research committee and with the 1964 Helsinki declaration and its later amendments or comparable ethical standards.

\section{Statistical analysis}

Normally distributed data are presented as mean \pm standard deviation; non-normally distributed data are presented as median and interquartile range. Categorical data are presented as frequency and percentage. Departure from normality assumption was assessed by the Kolmogorov-Smirnov test. Chi-square or Fisher's exact tests were used to show that whether the two categorical variables are independent. Between group differences were assessed using the t-test and ANOVA for normally distributed continuous data and Mann-Withney U test was also used in case on non-normal distributed data. To investigate the predictors of UIC deficiency and subsequent neonatal outcomes, multivariate binary and ordinal logistic regression models by the backward stepwise method by adjusting the probable confounders were undertaken. Analyses were performed using STATA $13 \mathrm{MP}$ and a $p<0.05$ was considered statistically significant.

\section{Results}

The data from 884 mothers in their third trimester of pregnancy who had attended medical centres to terminate their pregnancies are used in this study. The mean \pm standard deviation of the ages of the participants was $29.14 \pm 2.5$. Besides, the age pregnancy in the attending mothers were $38.4 \pm 7.3$ weeks gestational age. The median (IQR) urinary iodine concentration in the third trimester was 176 (165-196) micrograms/litre. Table 1 demonstrates the demographic information of the participants.

The results showed that out of 884 participants 838 (94.8\%) had a urinary iodine concentration of more than 150 micrograms/litre and 46 (5.2\%) showed urinary iodine concentrations less than 150 micrograms/litre. Assessment of the demographic variables of the two groups showed a statistically significance difference regarding the type of pregnancy (Planned vs. unPlanned), the use of dietary complements during pregnancy, the weight gained during pregnancy, the timing between the two most recent pregnancies and mother's level of education. The results of multivariate logistic regression analysis used to assess the effects of possible variables influencing low urinary iodine concentration in the third trimester of pregnancy are shown in Table 2.

The results of the aforementioned model show that every kilogram of weight gain during pregnancy has led to decreased odds of low urinary concentrations of iodine during the third pregnancy trimester of up to $13 \%$. Moreover, with every one more year added to the time interval between the two most recent pregnancies led to a $20 \%$ of decrease of low urinary iodine concentrations. Besides, the odds of urinary iodine concentrations of lower the 150 micrograms/litre was 3.3 times more in those with unplanned pregnancies compared to those who experienced desired pregnancies. When assessed in accordance with the WHO criteria 46 of the participants 
Table 1 Demographic information of studied participants based on iodine status

\begin{tabular}{|c|c|c|c|c|}
\hline \multirow[t]{2}{*}{ Variables } & Urinary lodine $<150 \mu \mathrm{g} / \mathrm{l}$ & Urinary lodine $\geq 150 \mu \mathrm{g} / \mathrm{l}$ & All participants & $P$-value \\
\hline & Mean(SD), N(\%) & Mean(SD), N(\%) & \multicolumn{2}{|l|}{ Mean(SD), N(\%) } \\
\hline Urinary iodine concentration $(\mu \mathrm{g} / \mathrm{l})$ & $131.3(130-137)$ & $176(165-197)$ & $176(165-196)$ & $<0.001$ \\
\hline Age (years) & $29.3 \pm 4.9$ & $29.2 \pm 14.8$ & $29.2 \pm 14.5$ & 0.91 \\
\hline No. of live deliveries & $1.47 \pm 0.89$ & $1.73 \pm 0.86$ & $1.71 \pm 0.87$ & 0.091 \\
\hline No. of previous pregnancies & $1.91 \pm 0.91$ & $2.07 \pm 1$ & $2.06 \pm 1$ & 0.25 \\
\hline Weight before pregnancy (Kg) & $62.4 \pm 11.2$ & $64.5 \pm 20.3$ & $64.3 \pm 19.9$ & 0.25 \\
\hline The timing between the two most recent pregnancies (year) & $3.25 \pm 0.29$ & $4.57 \pm 0.15$ & $4.5 \pm 0.14$ & 0.002 \\
\hline Weight gain during pregnancy $(\mathrm{Kg})$ & $9 \pm 5$ & $12.8 \pm 5.5$ & $12.6 \pm 5.6$ & $<0.001$ \\
\hline \multicolumn{5}{|l|}{ Type of pregnancy } \\
\hline Planned & $25(4.0)$ & $600(96)$ & $625(72.93)$ & \multirow[t]{2}{*}{0.004} \\
\hline unplanned & $21(9.05)$ & $211(90.95)$ & $232(27.07)$ & \\
\hline \multicolumn{5}{|l|}{ Mother's level of education } \\
\hline Illiterate & $2(8.3)$ & $22(91.7)$ & $24(2.72)$ & \multirow[t]{4}{*}{$<0.001$} \\
\hline Senior high & $27(12)$ & $198(88)$ & $225(25.5)$ & \\
\hline B.S. & $16(2.6)$ & $606(97.6)$ & $622(70.5)$ & \\
\hline M.S. or higher & $1(9)$ & $10(91)$ & $11(1.25)$ & \\
\hline \multicolumn{5}{|l|}{ lodinated salt consumption } \\
\hline yes & $41(5.2)$ & $751(94.8)$ & $792(89.59)$ & \multirow[t]{2}{*}{0.91} \\
\hline no & $5(5.4)$ & $87(94.6)$ & $92(10.41)$ & \\
\hline \multicolumn{5}{|l|}{ Complement intake during pregnancy } \\
\hline yes & $32(4)$ & 775 (96) & $807(91.22)$ & \multirow[t]{2}{*}{$<0.001$} \\
\hline No & $14(18.2)$ & $63(81.8)$ & $77(8.71)$ & \\
\hline \multicolumn{5}{|l|}{ Fish consumption } \\
\hline yes & $34(5.06)$ & $638(94.94)$ & $672(77.51)$ & \multirow[t]{2}{*}{0.54} \\
\hline No & $12(6.15)$ & $183(93.85)$ & $195(22.49)$ & \\
\hline \multicolumn{5}{|l|}{ Egg consumption } \\
\hline Twice weekly & $30(5.3)$ & $539(94.7)$ & $569(66.09)$ & \multirow[t]{2}{*}{0.93} \\
\hline Less than twice per week & $15(5.1)$ & 277 (94.9) & $292(33.91)$ & \\
\hline
\end{tabular}

(5.2\%) had insufficient urinary iodine concentrations, 805 (91.06\%) had adequate urinary iodine concentrations while 33 (3.73) showed more than adequate levels. There were no participants with urinary iodine concentrations higher than 500 micrograms/litre.

Assessing the neonatal complications showed that out of 884 neonates 29 (3.28\%) suffered from severe neonatal hypothyroidism, 202 (22.85) had moderate hypothyroidism and the remainder had no dysfunction of the thyroid gland. The remainder of the maternal and neonatal complications are shown in Table 3.

This table demonstrates meaningful differences between the results of the univariate analyses concerning, preterm birth, NICU admission, neonatal hypothyroidism between the newborns of the mothers with urinary iodine concentrations higher than 150 micrograms/litre and those with lower concentrations. Besides, there was no significant relationship between the APGAR score at birth and urinary iodine concentration (0.11).

Table 4 shows the results of multivariate logistic regression performed to assess the relation of maternal urinary iodine concentrations and neonatal complications, adjusted for interfering variables. No relationship of significance was found between maternal urinary iodine concentrations and other outcomes.

After adjusting the effects of confounding vaiables, the above-mentioned models showed that iodine deficiency in pregnant women has a strong relation with NICU admissions of the neonates and preterm births, so much so that inadequate urinary iodine concentrations led to a 4.6 times increase in NICU admissions and a 3.3 times increase in preterm births (results of full models along with all adjusted variables are available upon the request). The one way analysis of variance (ANOVA) 
Table 2 Assessment of the effects of variables causing iodine urinary concentrations lowers than 150 micrograms/litre

\begin{tabular}{|c|c|c|c|c|c|c|}
\hline \multirow[t]{2}{*}{ Variables } & \multicolumn{2}{|l|}{ Model $1^{\mathrm{a}}$} & \multicolumn{2}{|l|}{ Model $2^{b}$} & \multicolumn{2}{|l|}{ Model $3^{c}$} \\
\hline & $(\mathrm{OR}, 95 \% \mathrm{Cl})$ & $P$-value & $(\mathrm{AOR}, 95 \% \mathrm{Cl})$ & $P$-value & $(\mathrm{AOR}, 95 \% \mathrm{Cl})$ & $P$-value \\
\hline Age (years) & $1.0(0.98-1.02)$ & 0.96 & $1.005(0.98-1.02)$ & 0.65 & - & - \\
\hline No. of live deliveries & $0.67(0.43-1.04)$ & 0.079 & $0.85(0.35-1.19)$ & 0.24 & - & - \\
\hline No. of previous pregnancies & $0.84(0.61-1.15)$ & 0.29 & $0.63(0.30-1.35)$ & 0.16 & $0.59(0.39-0.89)$ & 0.012 \\
\hline Weight gain during pregnancy & $0.86(0.8-0.92)$ & $<0.001$ & $0.88(0.82-0.95)$ & 0.002 & $0.87(0.83-0.95)$ & 0.002 \\
\hline The timing between the recent two pregnancies & $0.80(0.68-0.94)$ & 0.007 & $0.78(0.64-0.95)$ & 0.014 & $0.8(0.68-0.95)$ & 0.015 \\
\hline \multicolumn{7}{|l|}{ Type of pregnancy } \\
\hline Planned & Reference & - & Reference & - & Reference & - \\
\hline Unplanned & $2.38(1.30-4.35)$ & 0.005 & $2.92(1.29-6.58)$ & 0.01 & $3.3(1.65-6.63)$ & 0.001 \\
\hline \multicolumn{7}{|l|}{ Mother's level of education } \\
\hline Illiterate & Reference & - & Reference & - & Reference & - \\
\hline Senior high & $0.88(0.19-4.1)$ & 0.88 & $0.22(0.04-1.35)$ & 0.11 & - & - \\
\hline M.S. & $0.49(0.1-2.1)$ & 0.35 & $0.13(0.3-0.73)$ & 0.022 & - & - \\
\hline B.S or higher & $1.1(0.09-13.5)$ & 0.94 & $0.1(0.05-1.79)$ & 0.11 & - & - \\
\hline \multicolumn{7}{|l|}{ lodinated salt intake } \\
\hline Yes & Reference & - & Reference & - & Reference & - \\
\hline No & $1.05(0.40-2.73)$ & 0.91 & $0.91(0.11-2.29)$ & 0.38 & - & - \\
\hline \multicolumn{7}{|l|}{ Complement intake during pregnancy } \\
\hline Yes & Reference & - & Reference & - & Reference & - \\
\hline No & $5.38(2.73-10.6)$ & $<0.001$ & $3.64(1.44-9.1)$ & 0.006 & $4.8(2.1-10.1)$ & $<0.001$ \\
\hline \multicolumn{7}{|l|}{ Fish consumption } \\
\hline Yes & Reference & - & Reference & - & Reference & - \\
\hline No & $0.81(0.41-1.6)$ & 0.54 & $0.89(0.41-1.56)$ & 0.58 & - & - \\
\hline
\end{tabular}

a univariate model

b full model by enter method

c backward stepwise model

showed that there are no statistical differences $(p=0.47)$ between the mean maternal urinary iodine concentration in different maternal complications of pregnancy (Fig. 1). Figure 1 showed the differences between the mean level of UIC in different maternal complications.

\section{Discussion}

Our study demonstrated a prevalence of maternal iodine deficiency of $5.2 \%$, as is defined by WHO, with a mean urinary iodine concentration of 131.3 (130-137) micrograms/litre. The main influencing factors on maternal iodine deficiency in this study were weight gain during pregnancy, the interval between the most recent pregnancies, whether or not the pregnancy has been Planned, mother's level of education, and nutritional complement consumption. The need for a NICU admission, preterm birth and neonatal hypothyroidism were significantly related with maternal iodine deficiency before delivery.

According to WHO, ICCIDD and UNICEF guidelines there is no need for iodine complements in countries that iodinated salt is consistently consumed [17]. However, studies have shown that even in countries with consistent iodinated salt use $50 \%$ of pregnant women have urinary iodine concentrations below 150 micrograms/litre [18]. A recent study in Iran showed that the Iranian community has enough iodine intakes and has all of the IDD criteria for optimum control of iodine deficiency [19]. However, the same study showed that nearly $5 \%$ of the pregnant women participating in that study suffered from iodine deficiency. The results of a study in 2016 on the third-trimester iodine concentrations in pregnant women showed a $26.4 \%$ of urinary iodine concentrations below 150 and $28.7 \%$ below 100 micrograms/litre [20]. As this study took place in Tehran and in a specific group of pregnant women (third trimester), the differences in the prevalence can be attributed to the sampling methods and a much wider study environment..

Zimmermann et al. [21] carried out a study in European countries and found that iodine intakes during pregnancy were sufficient in ten countries and in 21 countries were insufficient. The results of a study conducted on 1525 mother-child pairs in the Netherlands revealed that $12.3 \%$ pregnant women had UIC $<150 \mu \mathrm{g} / \mathrm{g}$ creatinine in early 
Table 3 Association between neonatal complications and level of lodine concentrations during the third trimester among pregnant women in Tehran

\begin{tabular}{|c|c|c|c|c|}
\hline Type of complication & Category & $\mathrm{UIC} \geq 150 \mu \mathrm{g} / \mathrm{I}(n=838)$ & $\mathrm{UIC}<150 \mu \mathrm{g} / \mathrm{I}(n=46)$ & $P$-value ${ }^{1,2}$ \\
\hline \multirow[t]{2}{*}{ Hypocalcaemia induced seizure } & No & $822(92.99)$ & $46(5.2)$ & 0.34 \\
\hline & Yes & $16(1.81)$ & $0(0)$ & \\
\hline \multirow[t]{3}{*}{ Neonatal hypothyroidism } & No & $628(71.04)$ & $25(2.83)$ & $<0.001$ \\
\hline & Moderate & $194(21.95)$ & $8(0.9)$ & \\
\hline & Severe & $16(1.81)$ & $13(1.47)$ & \\
\hline \multirow[t]{2}{*}{ Anatomical congenital anomalies } & No & $809(91.5)$ & $45(5.09)$ & 0.639 \\
\hline & Yes & $29(3.28)$ & $1(0.11)$ & \\
\hline \multirow[t]{2}{*}{ Hyperbilirubinemia } & No & $777(87.9)$ & $40(4.52)$ & 0.15 \\
\hline & Yes & $61(6.9)$ & $6(0.68)$ & \\
\hline \multirow[t]{2}{*}{ RDS } & No & $806(91.18)$ & $44(4.98)$ & 0.85 \\
\hline & Yes & $32(3.62)$ & $2(0.23)$ & \\
\hline \multirow[t]{2}{*}{ NICU } & No & $783(88.57)$ & $38(4.3)$ & 0.005 \\
\hline & Yes & $55(6.22)$ & $8(0.9)$ & \\
\hline \multirow[t]{2}{*}{ Gestational age (week) } & $<37$ & $96(10.85)$ & $12(1.35)$ & 0.008 \\
\hline & $\geq 37$ & 742 (83.9) & $34(3.84)$ & \\
\hline Apgar score at birth & Mean (SD) & $8.86 \pm 0.6$ & $8.82 \pm 56$ & $0.71^{2}$ \\
\hline Apgar score at $5 \mathrm{~min}$ & Mean (SD) & $9.8 \pm 1.2$ & $9.7 \pm 1.1$ & $0.91^{2}$ \\
\hline
\end{tabular}

1 Chi-square test 2 Independent t-test

pregnancy [22]. In another study on pregnant women in the rural area of Bangladesh, the prevalence of inadequate iodine intake was reported to be $6 \%$ and excessive iodine intake was $10 \%$ [23]. Zoysa et al. [24] in their study depicted that the prevalence of trimester-specific insufficient intake of urinary iodine in line with the World Health Organization criteria were $34.7,45$ and $62.2 \%$ in first, second, and third trimesters, respectively. These results were very similar to those of the present study, but the prevalence in the third trimester was less prevalent in the current study. Also, in Rajput et al.' study [25], the median urinary iodine less than $150 \mu \mathrm{g} / \mathrm{L}$ among euthyroid pregnant women were 43.82, 54.08, and $62.24 \%$ in first,

Table 4 Multiple regression analysis of lodine insufficiency effects on neonatal outcomes

\begin{tabular}{lll}
\hline Outcomes & AOR, 95\% Cl & $P$-value \\
\hline NICU admission & & 0.001 \\
Preterm birth $^{2}$ & $4.64(1.81-11.9)$ & 0.003 \\
Neonatal hypothyroidism $^{3}$ & $3.29(1.51-7.1)$ & 0.083
\end{tabular}

1 This model was adjusted for maternal age, parity, pregnancy type, mother education, recent pregnancy time interval, weight gain during pregnancy, delivery type, smoking, Birth weight and Apgar score

2 This model was adjusted for maternal age, parity, pregnancy type, mother education, recent pregnancy time interval, weight gain during pregnancy and smoking

3 This model was adjusted for maternal age, parity, pregnancy type, mother education, recent pregnancy time interval, weight gain during pregnancy, delivery type, smoking and Birth weight

4 Derived from ordinal logistic regression second, and third trimesters, respectively. Not only excessive iodine intake but also its deficiency can enhance the risk of goitre; based on a meta-analysis, a U-shaped association between UIC and goitre prevalence among schoolage children can be observed [26].

Iodine deficiency during pregnancy has been one of the major problems in public health that affects developed and developing countries [27]. The importance of this issue arises from the fact that it affects the health of the mother and child and increases the financial burden related to this condition worldwide [28]. With effective interventions such as iodinating the dietary salt, educating pregnant women and proper coordination between medical and health departments, this problem can be prevented $[29,30]$. Defining the causative chain of iodine deficiency during pregnancy and factors affecting it are necessary in order to prevent maternal iodine deficiency. In our study, there was a $13 \%$ decline with every onekilogram weight gain during pregnancy. It appears that weight gain, as a proxy of proper diet, has protective activity against iodine deficiency [1]. Besides, there were meaningful relations between timing interval between most recent pregnancies, the desirability of the pregnancy, use nutritional micronutrients before and during pregnancy and mother's level education and urinary iodine concentration. In a study in Ethiopia age, multiparity and mother's level of education were found to be significantly related to maternal iodine content during pregnancy [31]. In another study in China the type of dietary salt, maternal 


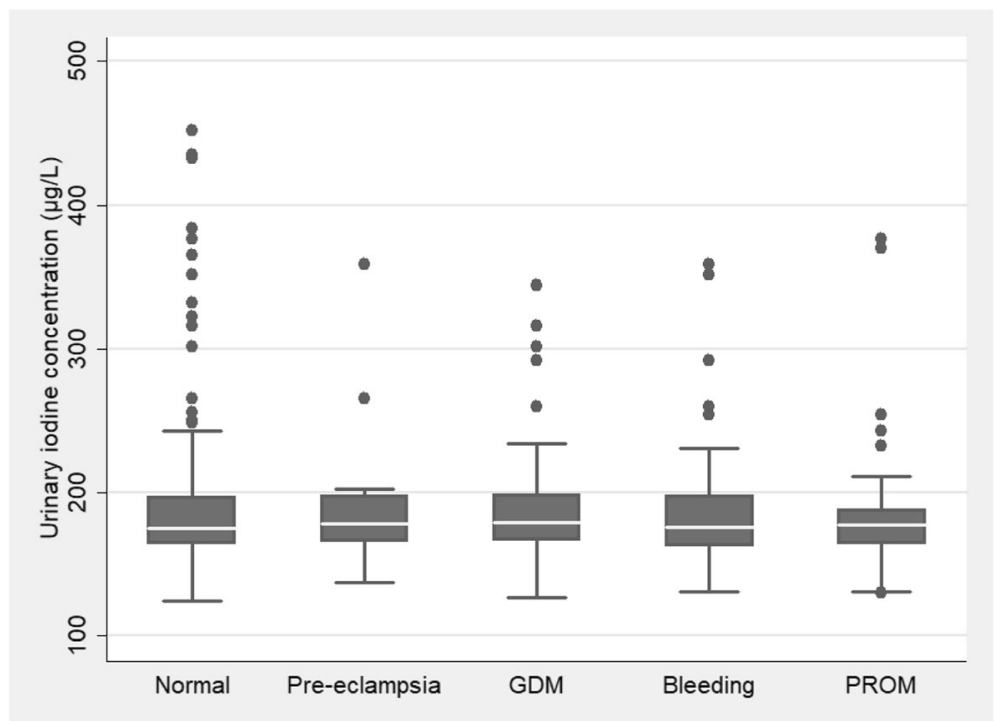

Fig. 1 Mean level of urinary iodine concentration in different maternal complications

age, occupation, consumption of complementary micronutrients and seafood were found to affect urinary iodine meaningfully [32]. In another study by Dineva et al. seafood consumption, iodinated salt intake and maternal age were found to be defining factors in urinary iodine concentration of the mother [33]. However, this study did not find any relation of statistical significance between maternal iodine deficiency and maternal complications of the pregnancy. Trolinska et al. did not find a relationship between iodine levels during pregnancy and maternal complications of the pregnancy, however, they proposed a larger study to assess the relationship [34].

The World Health Organization suggested the use of $250 \mathrm{mcg}$ of daily iodine during pregnancy and lactation, and the United States Institute of Medicine (IOM) suggested $220 \mathrm{mcg}$ of daily iodine during pregnancy and $290 \mathrm{mcg}$ of daily iodine during lactation [17, 35]. There are associations between iodine deficiency during pregnancy and some complications including congenital anomalies, stillbirth, abortion, impair neurological development of the fetus, and irreversible fetal brain damage [36-39]. Geographic area, ethnicity, and different environmental factors affect the pattern of thyroid dysfunction. Thus, taking the importance of iodine in the health of the mother and the child into account, we must verify the urinary iodine status in various conditions.

Using a multivariate logistic regression in this study showed that neonate of mothers with urinary iodine levels below 150 micrograms/litre were 4.6 times more hospitalised in NICU and preterm outcome for the neonates of mothers with UIC below 150 micrograms/litre were 3.3 times more frequent in comparison with referent group. In a recent study in three major cities across the
UK, researchers found no relation between iodine deficiency and low birth weight and preterm labour [40]. Walsh et al. did not find any relation between maternal low iodine intake and perinatal mortality and neural development of the neonates of these mothers [41].

Urinary iodine is considered as a non-invasive and efficient index for the population iodine status. Due to the fact that the majority of the absorbed iodine is excreted in the urine, urinary iodine can be regarded as a suitable indicator of recent iodine intake [42]. A single spot urine sample was used in this study. Single spot urine samples were recommended by WHO/UNICEF/ICCIDD for measuring the population iodine status [37]. Single spot urine samples in comparison with 24-h samples or multiple samples are easier in practice and based on a review, the results of spot urine samples are a valid indicator for measuring the population iodine status [43].

While this study with its large sample volume can be a good representation of the urban Tehran women, the existence of different racial minorities and ethnicities has created the need to repeat the study on other populations across the country. On the other hand, this study has focused on third-trimester mothers until delivery, while devising a study that includes the whole length of pregnancy can lead to a better assessment of the effects of maternal iodine concentrations during pregnancy on maternal and neonatal outcomes. Having had the thyroid function tests performed, we could have presented them as a complement to the current results.

\section{Conclusions}

This study shows that despite implementation of iodized salt strategies in Iran approximately $5 \%$ of the pregnant 
population suffer from perinatal urinary iodine concentrations below 150 micrograms/litre. Iodine deficiency complication in pregnant women can be decreased by appropriate planning for pregnancy such as the planning for pregnancy, proper time intervals between pregnancies ( $>12$ months to $<5$ years) $[44,45]$, appropriate nutrition during pregnancy. Besides, controlling maternal urinary iodine concentrations is important to prevent neonatal complications such as preterm delivery and NICU admission. Monitoring of iodine concentration at the population level and iodine replacement may be needed during pregnancy.

\section{Abbreviations}

OR: Odd Ratios; AOR: Adjusted odds ratio; Cl: Confidence Interval; NICU: Neonate Intensive care unit; RDS: Respiratory disease syndrome; PROM: Premature rapture of membrane; GDM: Gestational diabetes mellitus

\section{Acknowledgements}

The authors would like to thank data collectors and the study participants for their dedicated cooperation and made the study possible.

\section{Authors' contributions}

SSG and MB carried out the study starting from conception, analysis and interpretation of data and drafting of the manuscript. MBB, RF and MS participated in analysis and interpretation of data for important intellectual content and MM participated in critical review of the manuscript, data analysis and interpretation of the finding. All authors have read and approved the final version of the manuscript.

\section{Funding}

There is no source of found for this study.

\section{Availability of data and materials}

All relevant data were available upon the reasonable request.

\section{Ethics approval and consent to participate}

Ethical clearance was obtained from the Institutional Review Board (IRB) of the Shahid Beheshti University of Medical Science, prior to the commencement of the data collection. Participants were informed about the purpose of the study and written informed consent was obtained from all participants.

\section{Consent for publication}

Not applicable.

\section{Competing interests}

The authors declare that they have no competing interests.

\section{Author details}

'Department of Gynecology \& Obstetrics, Shohada Tajrish Educationa Hospital, Shahid Beheshti University of Medical Sciences, Tehran, Iran. 2Department of Gynecology \& Obstetrics, Mahdiyeh Hospital, Shahid Beheshti University of Medical Sciences, Tehran, Iran. ${ }^{3}$ Non-Communicable Diseases Research Center, Alborz University of Medical Sciences, Karaj, Iran. ${ }^{4}$ Department of Community Medicine, Alborz University of Medical Sciences, Karaj, Iran.

Received: 18 July 2019 Accepted: 9 March 2020

Published online: 18 March 2020

\section{References}

1. Harika R, Faber M, Samuel F, Kimiywe J, Mulugeta A, Eilander A Micronutrient status and dietary intake of iron, vitamin $a$, iodine, folate and zinc in women of reproductive age and pregnant women in Ethiopia, Kenya, Nigeria and South Africa: a systematic review of data from 2005 to 2015. Nutrients. 2017;9:1096.

2. Zimmermann MB. The importance of adequate iodine during pregnancy and infancy. Hidden Hunger: Karger Publishers; 2016. p. 118.
3. Zegler S. lodine Deficiency Disorders. Ann Transplant. 2014;19:499.

4. Glinoer D. The importance of iodine nutrition during pregnancy. Public Health Nutr. 2007;10:1542.

5. Andersen S, Karmisholt J, Pedersen KM, Laurberg P. Reliability of studies of iodine intake and recommendations for number of samples in groups and in individuals. Br J Nutr. 2008:99:813.

6. König F, Andersson M, Hotz K, Aeberli I, Zimmermann MB. Ten repeat collections for urinary iodine from spot samples or 24-hour samples are needed to reliably estimate individual iodine status in women-4. J Nutr. 2011;141:2049.

7. De Groot L, Abalovich M, Alexander EK, Amino N, Barbour L, Cobin RH, et al. Management of thyroid dysfunction during pregnancy and postpartum: an Endocrine Society clinical practice guideline. J Clin Endocrinol Metab. 2012; 97:2543.

8. Delange F. lodine requirements during pregnancy, lactation and the neonatal period and indicators of optimal iodine nutrition. Public Health Nutr. 2007;10:1571.

9. Korevaar TI, Muetzel R, Medici M, Chaker L, Jaddoe WW, de Rijke YB, et al. Association of maternal thyroid function during early pregnancy with offspring IQ and brain morphology in childhood: a population-based prospective cohort study. Lancet Diabetes Endocrinol. 2016;4:35.

10. Bath SC, Walter A, Taylor A, Wright J, Rayman MP. Iodine deficiency in pregnant women living in the south east of the UK: the influence of diet and nutritional supplements on iodine status. Br J Nutr. 2014;111:1622.

11. Granfors M. Hypothyroidism and pregnancy. Acta Universitatis Upsaliensis; 2015.

12. Haugen BR, Alexander EK, Bible KC, Doherty GM, Mandel SJ, Nikiforov YE, et al. 2015 American Thyroid Association management guidelines for adult patients with thyroid nodules and differentiated thyroid cancer: the American Thyroid Association guidelines task force on thyroid nodules and differentiated thyroid cancer. Thyroid. 2016;26:1.

13. Moreno-Reyes R, Glinoer D, Van Oyen H, Vandevijvere S. High prevalence of thyroid disorders in pregnant women in a mildly iodine-deficient country: a population-based study. J Clin Endocrinol Metab. 2013:98:3694.

14. Olivares JL, Olivi Gl, Verdasco C, Ortiz VA, Mayer MA, Cresto JC. Low iodine intake during pregnancy: relationship to placental development and head circumference in newborn. Endocrinología y Nutrición. 2012;59:326.

15. Léger J, Olivieri A, Donaldson M, Torresani T, Krude H, van Vliet G, et al. Clinical practice guideline: European Society for Paediatric Endocrinology Consensus Guidelines on screening, diagnosis, and Management of Congenital Hypothyroidism. J Clin Endocrinol Metab. 2014;99:363.

16. Organization $\mathbf{W H}$. Urinary iodine concentrations for determining iodine status in populations. World Health Organizations; 2013.

17. Secretariat W, Andersson M, De Benoist B, Delange F, Zupan J. Prevention and control of iodine deficiency in pregnant and lactating women and in children less than 2-years-old: conclusions and recommendations of the technical consultation. Public Health Nutr. 2007;10:1606.

18. Caldwell KL, Pan Y, Mortensen ME, Makhmudov A, Merrill L, Moye J. lodine status in pregnant women in the National Children's study and in US women (15-44 years), National Health and nutrition examination survey 2005-2010. Thyroid. 2013;23:927.

19. Delshad H, Mirmiran P, Abdollahi Z, Salehi F, Azizi F. Continuously sustained elimination of iodine deficiency: a quarter of a century success in the Islamic Republic of Iran. J Endocrinol Investig. 2018;41:1089.

20. Delshad H, Touhidi M, Abdollahi Z, Hedayati M, Salehi F, Azizi F. Inadequate iodine nutrition of pregnant women in an area of iodine sufficiency. J Endocrinol Investig. 2016:39:755.

21. Zimmermann MB, Gizak M, Abbott $K$, Andersson M, Lazarus JH. lodine deficiency in pregnant women in Europe. Lancet Diabetes Endocrinol. 2015;3:672.

22. Ghassabian A, Steenweg-de Graaff J, Peeters RP, Ross HA, Jaddoe WW, Hofman A, et al. Maternal urinary iodine concentration in pregnancy and children's cognition: results from a population-based birth cohort in an iodine-sufficient area.BMJ Open 2014;4:e005520. https://doi.org/10.1136/ bmjopen-2014-005520.

23. Rydbeck F, Bottai M, Tofail F, Persson L- $\AA$, Kippler M. Urinary iodine concentrations of pregnant women in rural Bangladesh: a longitudinal study. J Exp Sci Environ Epidemiol. 2014;24:504.

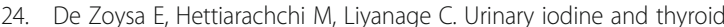
determinants in pregnancy: a follow up study in Sri Lanka. BMC Pregnancy Childbirth. 2016:16:303

25. Rajesh R, Laxminarayan Y, Smiti N, Rashmi Y. Trimester specific nutritional status of iodine among Euthyroid pregnant women. Thyroid Disorder Ther. 2017;6:2. 
26. Xiu L, Zhong G, Ma X. Urinary iodine concentration (UIC) could be a promising biomarker for predicting goiter among school-age children: a systematic review and meta-analysis. PLoS One. 2017;12:e0174095.

27. Zimmermann MB, Jooste PL, Pandav CS. Iodine-deficiency disorders. Lancet. 2008;372(9645):1251-62.

28. Christian P, Smith ER. Adolescent undernutrition: global burden, physiology, and nutritional risks. Ann Nutr Metab. 2018;72:316.

29. Su X, Li M, Liu L, Shen H, Kelly PJ, Wang Y, et al. Assessment of thyroid function in children, adults and pregnant and lactating women after longterm salt iodisation measurements. Br J Nutr. 2018;119(11):1245-53.

30. Watutantrige-Fernando S, Barollo S, Bertazza L, Cavedon E, Censi S, Manso J, et al. Efficacy of educational intervention to improve awareness of the importance of iodine, use of iodized salt, and dietary iodine intake in northeastern Italian schoolchildren. Nutrition. 2018;53:134.

31. Fereja M, Gebremedhin S, Gebreegziabher T, Girma M, Stoecker BJ. Prevalence of iodine deficiency and associated factors among pregnant women in Ada district, Oromia region, Ethiopia: a cross-sectional study. BMC Pregnancy Childbirth. 2018;18:257.

32. Wei Z, Wang $W$, Zhang J, Zhang $X$, Jin L, Yu X. Urinary iodine level and its determinants in pregnant women of Shanghai, China. Br J Nutr. 2015;113: 1427.

33. Dineva M, Rayman MP, Levie D, Guxens M, Peeters RP, Vioque J, et al. Similarities and differences of dietary and other determinants of iodine status in pregnant women from three European birth cohorts. Eur J Nutr. 2020;59:371-87.

34. Torlinska B, Bath S, Janjua A, Boelaert K, Chan S-Y. lodine status during pregnancy in a region of mild-to-moderate iodine deficiency is not associated with adverse obstetric outcomes; results from the Avon longitudinal study of parents and children (ALSPAC). Nutrients. 2018;10:291.

35. Food and Nutrition Board Institute of Medicine. Dietary reference intake. Washington, DC: National Academy Press; 2001.

36. de Escobar GM, Obregon MJ, del Rey FE. lodine deficiency and brain development in the first half of pregnancy. Public Health Nutr. 2007;10:1554.

37. WHO/UNICEF/ICCIDD. Assessment of iodine deficiency disorders and monitoring their elimination: a guide for programme managers. 3rd ed. Geneva: World Health Organization; 2007. (http://whqlibdocwhoint/ publications/2007/9789241595827_engpdf, Accessed 19 Jan 2018) 2007.

38. Knight BA, Shields BM, He X, Pearce EN, Braverman LE, Sturley R, et al. lodine deficiency amongst pregnant women in south-West England. Clin Endocrinol. 2017;86:451.

39. Granfors M, Andersson M, Stinca S, Åkerud H, Skalkidou A, Sundström Poromaa I, et al. lodine deficiency in a study population of pregnant women in Sweden. Acta Obstet Gynecol Scand. 2015;94:1168.

40. Snart CJ, Keeble C, Taylor E, Cade JE, Stewart PM, Zimmermann M, et al. Maternal iodine status and associations with birth outcomes in three major cities in the United Kingdom. Nutrients. 2019;11:441.

41. Walsh V, Brown JVE, McGuire W. lodine supplementation for the prevention of mortality and adverse neurodevelopmental outcomes in preterm infants. Cochrane Database of Systematic Reviews; 2019.

42. World Health Organization. Urinary iodine concentrations for determining iodine status deficiency in populations. Vitamin and Mineral Nutrition Information System. Geneva: World Health Organization; 2013. (http://www. who.int/nutrition/vmnis/indicators/urinaryiodine, Accessed [20 Jan 2018]).

43. Rohner F, Zimmermann M, Jooste P, Pandav C, Caldwell K, Raghavan R, et al. Biomarkers of nutrition for development--iodine review. J Nutr. 2014; 144:1322s.

44. Conde-Agudelo A, Rosas-Bermúdez A, Kafury-Goeta AC. Birth spacing and risk of adverse perinatal outcomes: a meta-analysis. Jama. 2006;295:1809.

45. Conde-Agudelo A, Rosas-Bermúdez A, Kafury-Goeta AC. Effects of birth spacing on maternal health: a systematic review. Am J Obstet Gynecol. 2007;196:297.

\section{Publisher's Note}

Springer Nature remains neutral with regard to jurisdictional claims in published maps and institutional affiliations.

Ready to submit your research? Choose BMC and benefit from:
- fast, convenient online submission
- thorough peer review by experienced researchers in your field
- rapid publication on acceptance
- support for research data, including large and complex data types
- gold Open Access which fosters wider collaboration and increased citations
- maximum visibility for your research: over 100M website views per year
At BMC, research is always in progress.
Learn more biomedcentral.com/submissions

